\title{
Emergency departments must not return to pre-covid days of overcrowding and lack of safety, says college
}

\author{
Adrian O'Dowd
}

London

UK emergency departments must never return to their previous state of being overcrowded, as well as being sources of hospital acquired infection and unsafe for staff to work in, experts have said.

The Royal College of Emergency Medicine issued a position statement on 6 May $^{1}$ in which it warned that, if the NHS allowed hospitals to return to the old model of emergency care as covid-19 cases start to fall, patients' lives would be put at risk.

The need for a "reset" in how care is delivered in emergency departments is vital to prevent a resurgence of covid-19 cases and to leave a permanent improvement in the care provided overall, it said.

Since the covid-19 pandemic began, emergency departments have seen a marked decline in overall demand. This includes a 25\% drop from 120356 attendances to 89584 in England in the week after lockdown (23-29 March), as compared with the previous week. $^{2}$

The college said that the pandemic had brought significant disruption to the way medical care was delivered in all areas of clinical practice. However, the NHS's "phenomenal" response had led to a rapid expansion of bed capacity, appropriate levels of staffing, different parts of hospitals working better together than before, new discharge practices for medically fit patients, better use of same day emergency care, and better use of NHS 111 - collectively resulting in a far more responsive emergency care system.

\section{Building on temporary practices}

The college's position statement said, "As we progress beyond the peak of this outbreak, we must take action now to ensure patient safety is never jeopardised again through poor infection control, design, physical crowding, inadequate staff protection, and corridor care."

Although the college welcomed signs of recovery from the first wave of the pandemic, it warned that the NHS was at the beginning of a period of essential transformation and set out recommendations on how to prevent further transmission of the virus in emergency departments, streamline emergency care, and build on current temporary practices.
The position statement said that hospitals and emergency departments must never become overcrowded again. In addition, emergency departments must not become reservoirs of infection for patients, must be designed to look after vulnerable patients safely, and must be safe workplaces for staff.

The college's president, Katherine Henderson, said, "It was just four months ago when we were seeing overcrowding on a record scale in emergency departments. It was unacceptable then and put lives at risk; to go back to that now will lead to avoidable patient and staff illness or death.

"Crowding has long been associated with avoidable mortality, and covid-19 reinforces and multiplies this risk. We must have a way to enforce social distancing in emergency departments to ensure that patients do not become infected while seeking healthcare. If supermarkets can get this right, then the very institution that people entrust with their health must do so too."

She added, "There is a need for wholesale change while embracing the new practices we've seen during this crisis. The NHS has coped magnificently so far despite facing many challenges, not least the supply of PPE [personal protective equipment], but has demonstrated an ability to optimise the delivery of care that puts patient safety first. We must learn from this response."

The college's statement was welcomed by Layla McCay, director at the NHS Confederation, which represents healthcare organisations, who said that the NHS needed to capture the innovations seen throughout the NHS during the pandemic. She said, "The clear message we have been hearing from health and care leaders and clinicians has been that this is an opportunity to reset the way we plan, commission, and deliver health and care."

1 Royal College of Emergency Medicine. Covid-19: Resetting emergency department care. 6 May 2020. https://www.rcem.ac.uk/docs/Policy/RCEM_Position_statement_Resetting_ Emergency_Care_200506.pdf.

2 Thornton J. Covid-19: A\&E visits in England fall by 25\% in week after lockdown. BMJ 2020;369:m1401. 10.1136/bmj.m1401 32253175

Published by the BMJ Publishing Group Limited. For permission to use (where not already granted under a licence) please go to http://group.bmj.com/group/rights-licensing/ permissions 